\title{
Spontaneous Rupture of Spleen in a Pregnant Armenian Woman with Favourable Pregnancy Outcome: Case Report
}

\author{
Norayr Ghukasyan \\ “Erebouni" Medical Center, Yerevan, Armenia \\ Email: norayrghukasyan2020@gmail.com
}

How to cite this paper: Ghukasyan, $\mathrm{N}$ (2021) Spontaneous Rupture of Spleen in a Pregnant Armenian Woman with Favourable Pregnancy Outcome: Case Report. Open Journal of Obstetrics and Gynecology, 11, 140-145.

https://doi.org/10.4236/ojog.2021.112016

Received: January 20, 2021

Accepted: February 22, 2021

Published: February 25, 2021

Copyright $\odot 2021$ by author(s) and Scientific Research Publishing Inc. This work is licensed under the Creative Commons Attribution International License (CC BY 4.0).

http://creativecommons.org/licenses/by/4.0/

\begin{abstract}
Background: Spontaneous or traumatic rupture of spleen in pregnancy is a rare event with catastrophic consequences. This report presents a case of spontaneous splenic rupture of a pregnant woman with thrombophilia in complicated somatic history and successful cesarean section with maternal and infant survival. Case: A 28-year-old Armenian woman at 35 weeks of gestation presented to the Emergency Department at "Erebouni" medical center in Yerevan, Armenia with sharp pain in the epigastric region, general weakness and worsening condition. The patient was immediately transferred to the operating room. All clinical-laboratory examinations were urgently carried out, the fetus condition began to be assessed under the control of the CT. She was in obvious distress with blood pressure of 90/50 $\mathrm{mm} \mathrm{Hg}$ and a pulse rate of 80 - 70 beats per minute. Abdominal ultrasound confirmed free fluid in the peritoneal cavity. Cesarean section was performed on the lower segment of the uterus. A live premature female infant was born weighing $2580 \mathrm{~g}$, height $48 \mathrm{~cm}$, and with an Apgar score of $7-8$ points. Then the integrity of the uterus was restored. Abdominal rehabilitation was performed, there were about $1000 \mathrm{ml}$ of blood loss and continuous internal bleeding. Doctors found splenic ruptures around the perineum. Lower middle laparotomy, splenectomy, abdominal rehabilitation, drainage were performed. Conclusion: This case illustrates the need to consider ruptured spleen as part of differential diagnosis of hemoperitoneum in pregnant women. Immediate surgical intervention is needed to ensure survival of mother and fetus.
\end{abstract}

\section{Keywords}

Pregnancy, Splenic Rupture, Obstetric Emergency 


\section{Introduction}

Splenic rupture is a potentially life-threatening complication usually occurring after blunt abdominal trauma or systemic disease (infectious mononucleosis, malaria, hematologic abnormalities, etc.). The risk and severity of injury is greatly increased by enlargement of the spleen, often accompanied with thinning of the capsule and creating a massive effect that makes it more fragile and vulnerable, with the inevitability of splenectomy in patients with splenomegaly. As we all know, spontaneous rupture of spleen without prior trauma or systemic disease occurs rare and the correct diagnosis is rarely done before surgery.

Various authors point to unintentional or intentional trauma as a non-obstetric cause of death among pregnant women in developed countries [1] [2] [3]. In severe injuries, the rate of fetal death may approach $60 \%$ whereas maternal deaths may occur in about $10 \%$ of cases [1]. Although about $90 \%$ of all traumas in pregnancy are minor and the rate of adverse pregnancy outcomes in minor trauma is $\sim 4 \%$, more fetuses die as a result of lesser injuries than as a result of catastrophic trauma [4] [5] [6]. Traumatic splenic rupture in pregnancy or postpartum is a rare and frequently misdiagnosed event. It may be as a result of trauma or from preexisting pathology of spleen. The first description of splenic rupture was presented by Saxtorph in 1803, with subsequent case reports few and far between [7]. Data from a review of 845 cases of ruptured spleen from 1980 to 2008 [8] demonstrate a much lower incidence of spontaneous rupture (about 7\%) than traumatic rupture of spleen (more than $93 \%$ of cases).

We present a case of spontaneous rupture in a pregnant woman with thrombophilia in complicated somatic history and successful cesarean section. The peer-reviewed scientific literature studied by us [1]-[14] describes isolated cases of spontaneous rupture of spleen in pregnant women. All of them were accompanied with the loss of fetus and/or the death of woman during labor. In our case, the mother and the fetus both are alive. In connection with the above, our observation may be of some interest.

\section{Case Presentation}

A 28-year-old Armenian woman presented to "Erebouni" medical center, Yerevan, Armenia with sharp pain in the epigastric region, general weakness and worsening condition. She had thrombophilia in complicated somatic history. She was in her first pregnancy and at 35 weeks of gestation. She noted that for several days she had mild pain in her left shoulder which still persisted. After lunch, she suddenly had sharp pain in the epigastric region, dizziness and her relative called an ambulance, 20 minutes later she was in the medical center.

All clinical-laboratory examinations were urgently carried out; the condition of the fetus began to be assessed under the control of the CT. Laboratory studies showed that $\mathrm{Hg}$ was $9.6 \mathrm{~g} / \mathrm{dL}$ (ref. $11.2-15.2 \mathrm{~g} / \mathrm{dL}$ ), and platelets were 828 $\mathrm{K} / \mathrm{mm}^{3}$ (ref. $180-400 \mathrm{~K} / \mathrm{mm}^{3}$ ). There was no time for in-depth examinations thus the first results were immediately taken into consideration. Within minutes 
the pregnant woman's condition deteriorated which was manifested with a brief loss of consciousness. At that moment the general condition was severe, the skin and visible mucous membranes were pale, breathing was rapid and shallow, the heart rate increased: tachycardia, the pulse weakened.

The abdomen was painful to the touch in the right groin, in the epigastric region. The uterus was slightly tense when touched. The fetus began to have a heartbeat up to 80 - 70 beats per minute, fetal distress and acute abdomen were diagnosed.

She was rushed to the operating room. Cesarean section was performed on the lower segment of the uterus. A live premature female infant was born weighing $2580 \mathrm{~g}$, height $48 \mathrm{~cm}$, and with an Apgar score of 7 - 8 points. Then the integrity of the uterus was restored. Abdominal rehabilitation was performed, there was about $1000 \mathrm{ml}$ of blood loss and continuous internal bleeding. Doctors found splenic rupture around the perineum. Lower middle laparotomy, splenectomy, abdominal rehabilitation, drainage were performed.

The patient spent the postoperative period in the intensive care unit, then was transferred to the postpartum department, received antibacterial, intestinal stimulants, anticoagulants and transfusion therapy. Post-operative wounds were healed within the prescribed period. Seven days later she was discharged in satisfactory condition with the special instructions of the gynecologist and surgeon.

On the $32^{\text {nd }}$ day after giving birth she complained of general weakness, worsening condition and pain in the right epigastric region. Appropriate clinical and instrumental examinations were performed and occlusive thrombosis of the splenic vein, upper mesenteric vein and portal vein was diagnosed.

Receiving inpatient conservative treatment by the decision of a vascular surgeon, general surgeon, gynecologist and hematologist she was discharged in satisfactory condition under the outpatient supervision of a vascular surgeon-hematologist.

\section{Discussion}

We present a case of spontaneous rupture in a pregnant woman with thrombophilia in complicated somatic history and successful cesarean section. This report provides data on a case of spontaneous rupture of spleen that occurred at a gestational age of 35 weeks. Spontaneous rupture of spleen is an extremely rare condition. Most cases of ruptured spleen during pregnancy in the reviewed literature/Pubmed database/are associated with 5 - 6 weeks of gestation, 72 cases in total, most of which relate to cases of splenic ectopic pregnancy and only a few refer to traumatic rupture of the spleen [9]-[16]. In our case, there was no proven traumatic injury to the spleen or the fact of violence that could cause and/or placental abruption and rupture of spleen.

The etiology of rupture has not yet been clarified. Intra-abdominal pressure such as coughing, sneezing, vomiting, jumping can cause a sharp increase in the abdominal cavity of the uterus, which in its turn can increase the pressure to the 
other intra-abdominal organs thus leading to the cause of spontaneous rupture of spleen. In addition, spontaneous rupture of spleen can occur for two reasons. The first one is the increased blood load in the abdominal cavity; a decrease in fluid volume makes the spleen more tender and traumatic. The second one, during pregnancy, is the increased level of estrogen and progesterone in the systemic circulation that can damage the structure of the spleen and even minor injuries can lead to rupture.

Diagnosis of a ruptured spleen in pregnancy, signs and symptoms in emergency obstetric situations such as rupture of uterus, placental abruption is very difficult because it is similar to other pathologies.

Among the situations that should be considered first in the differential diagnosis of the abdominal cavity, the most common symptom is abdominal pain on the left with radiation to left shoulder and chest. In most cases the diagnosis is made during an expulsion operation.

This is a high-risk situation. It will lead to fetal distress and the mother's hemodynamic can be disrupted very quickly.

\section{Conclusions}

Spontaneous rupture of spleen rarely occurs in the setting of a normal spleen during pregnancy. The diagnosis of splenic rupture in pregnancy is difficult to make as it shares signs and symptoms with a number of other conditions, such as uterine rupture and placental abruption. Early diagnosis and aggressive surgical intervention will allow for optimal maternal and perinatal outcomes. Through this case report, we want to draw attention to the fact that spontaneous rupture of a normal spleen is life-threatening condition which is difficult to diagnose.

The described clinical case proves the need to consider a ruptured spleen in the differential diagnosis of hemoperitoneum in pregnant women. In order to preserve the life of the mother and the fetus, immediate surgical intervention is necessary.

\section{Declaration of Patient Consent}

The authors certify that they have obtained all appropriate patient consent forms. In the form, the patient(s) has/have given her/their consent for her/their images and other clinical information to be reported in the journal. The patients understand that their names and initials will not be published and due efforts will be made to conceal their identity, but anonymity cannot be guaranteed.

\section{Conflicts of Interest}

The author declares no conflicts of interest regarding the publication of this paper. 


\section{References}

[1] Mirza, F.G., Devine, P.C. and Gaddipati, S. (2010) Trauma in Pregnancy: A Systematic Approach. American Journal of Perinatology, 27, 579-586.

https://doi.org/10.1055/s-0030-1249358

[2] El Kady, D. (2007) Perinatal Outcomes of Traumatic Injuries during Pregnancy. Clinical Obstetrics and Gynecology, 50, 582-591. https://doi.org/10.1097/GRF.0b013e31811eab82

[3] Mendez-Figueroa, H., Dahlke, J.D., Vrees, R.A. and Rouse, D.J. (2013) Trauma in Pregnancy: An Updated Systematic Review. American Journal of Obstetrics and Gynecology, 209, 1-10. https://doi.org/10.1016/j.ajog.2013.01.021

[4] Tohira, H., Jacobs, I., Mountain, D., Gibson, N. and Yeo, A. (2012) Systematic Review of Predictive Performance of Injury Severity Scoring Tools. Scandinavian Journal of Trauma, Resuscitation and Emergency Medicine, 20, 1-12. https://doi.org/10.1186/1757-7241-20-63

[5] Fildes, J., Reed, L. and Jones, N. (1992) Trauma: The Leading Cause of Maternal Death. The Journal of Trauma, 32, 643-645.

https://doi.org/10.1097/00005373-199205000-00017

[6] Van Hook, J.W. (2002) Trauma in Pregnancy. Clinical Obstetrics and Gynecology, 45, 414-424. https://doi.org/10.1097/00003081-200206000-00012

[7] De Graaff, J. and Piijpers, P.M. (1987) Spontaneous Rupture the Spleen in the Third Trimester of Pregnancy. Report of a Case and Review of Literature. European Journal of Obstetrics \& Gynecology and Reproductive Biology, 25, 243-247. https://doi.org/10.1016/0028-2243(87)90105-5

[8] Renzulli, P., Hostettler, A., Schepfer, A., Gloor, B. and Candinas, D. (2009) Systematic Review of a Traumatic Splenic Rupture. British Journal of Surgery, 96, 1114-1121. https://doi.org/10.1002/bjs.6737

[9] Adam, I. and Adam, E.S. (2007) Spontaneous Splenic Rupture in a Pregnant Sudanese Woman with Falciparum Malaria: A Case Report. Eastern Mediterranean Health Journal, 13, 735-736.

[10] Lieberman, M.E. and Levitt, M.A. (1989) Spontaneous Rupture of the Spleen: A Case Report and Literature Review. American Journal of Emergency Medicine, 7, 28-31. https://doi.org/10.1016/0735-6757(89)90079-X

[11] Fletcher, H., Frederick, J., Barned, H. and Lizarraga, V. (1989) Spontaneous Rupture of the Spleen in Pregnancy with Splenic Conservation. West Indian Medical Journal, 38, 114-115.

[12] Orloff, M.J. and Peskin, G.W. (1958) Spontaneous Rupture of the Normal Spleen; a Surgical Enigma. International Abstracts of Surgery, 106, 1-11.

[13] Wang, C., Tu, X., Li, S., Luo, G. and Norwitz, E.R. (2011) Spontaneous Rupture of the Spleen: A Rare but Serious Case of Acute Abdominal Pain in Pregnancy. The Journal of Emergency Medicine, 41, 503-506.

https://doi.org/10.1016/j.jemermed.2010.05.075

[14] Dave, A., Dhand, H. and Mujalde, A. (2012) Spontaneous Rupture of Spleen during Pregnancy. The Journal of Obstetrics and Gynecology of India, 62, 692-693. https://doi.org/10.1007/s13224-012-0141-0

[15] Al Inzi, S., Mohiyiddeen, G., Dalal, N., Pratap, C. and Gilmour, K. (2009) Spontaneous Rupture of the Spleen-A Fatal Complication of Pregnancy. Journal of Obstetrics and Gynaecology, 29, 555-556. 
https://doi.org/10.1080/01443610902888485

[16] Di Vella, G., Arpaio, A., Marzullo, A., et al. (2008) Rupture of the Spleen or Splenic Vessels (Splenic Emergency Syndrome) in Late Pregnancy: A Report of Two Autopsy Cases. Forensic Science International, 176, e1-e5.

https://doi.org/10.1016/j.forsciint.2007.06.018 